\title{
Docosahexaenoic acid regulates vascular endothelial cell function and prevents cardiovascular disease
}

\author{
Kazuo Yamagata
}

\begin{abstract}
Docosahexaenoic acid (DHA) is present in high concentrations in salmon, herring, and trout. Epidemiologic studies have shown that high dietary consumption of these and other oily fish is associated with reduced rates of myocardial infarction, atherosclerosis, and other ischemic pathologies. Atherosclerosis is induced by inflammation and can lead to acute cardiovascular events and extensive plaque. DHA inhibits the development of inflammation in endothelial cells, alters the function and regulation of vascular biomarkers, and reduces cardiovascular risk. It also affects vascular relaxation and constriction by controlling nitric oxide and endothelin 1 production in endothelial cells. DHA also contributes to the prevention of arteriosclerosis by regulating the expression of oxidized low density lipoprotein receptor 1, plasminogen activator inhibitor 1, thromboxane A2 receptor, and adhesion molecules such as vascular cell adhesion molecule-1, monocyte chemoattractant protein-1, and intercellular adhesion molecule 1 in endothelial cells. Recent research showed that DHA reduces the increase in adhesion factor expression induced by lipopolysaccharide by suppressing toll-like receptor 4. A new mechanism of action of DHA has been described that is mediated through endothelial free fatty acid receptor 4, associated with heme oxygenase 1 induction by Nrf2. However, the efficacy and mechanisms of action of DHA in cardiovascular disease prevention are not yet completely understood. The aim of this paper was to review the effects of DHA on vascular endothelial cells and recent findings on their potential for the prevention of circulatory diseases.
\end{abstract}

Keywords: DHA, Endothelial cells, Cardiovascular disease

\section{Background}

That a relation exists between cardiovascular disease (CVD) and omega-3 fatty acids (n-3 FA) first emerged in 1976 when Dyerberg et al. discovered that the Inuit of Greenland had a remarkably low incidence of CVD compared with the population of Denmark. A large difference in the consumption of eicosapentaenoic acid (EPA) and docosahexaenoic acid (DHA) was considered to be the principal underlying factor [1-4]. These early studies led to epidemiologic studies of cardiovascular disease prevention with n-3 FAs. However, some authors have questioned this conclusion. The main criticisms related to the systems used for health monitoring and for registration of the cause of death in Greenland $[5,6]$.

Correspondence: kyamagat@brs.nihon-u.ac.jp

Department of Food Bioscience and Biotechnology, College of Bioresourse,

Science, Nihon University (NUBS), 1866, Kameino, Fujisawa, Kanagawa 252-8510, Japan
Nevertheless, many epidemiologic and clinical studies have provided evidence that the polyunsaturated n-3 FA DHA in fish and fish oils provides cardiovascular disease protection. In several prospective cohort studies, the benefit ascribed to n-3 FA differed. The results were divided between those that were effective [7-10] and those that were not effective $[11,12]$. Consequently, a largescale meta-analysis of cohort studies was performed to examine the association between fish consumption and coronary heart disease mortality [13]. Based on 11 eligible studies and 13 cohorts (222,364 persons with an average 11.8 years of follow-up), fish intake was found to be inversely associated with the hazard ratio for coronary heart disease mortality. An increase in fish intake of $20 \mathrm{~g} /$ day was associated with a 7\% decrease in the risk of coronary heart disease mortality. Recently, in regard to the protective effect of n3-LCPUFA against CVD, a literature search was performed using PubMed and 
Medline entries between January 1, 2007 and August 31, 2013. Higher fish intake was associated with decreases in sudden cardiac death, stroke, myocardial infarction, and heart failure. These results supported the efficacy of 3 n-LCPUFA in hypertriglyceridemia and heart failure [14]. The results indicated efficacy of 3 n-LCPUFA for hypertriglyceridemia [14] and heart failure [15]. Alpha-linolenic acid (ALA) is a substrate for the synthesis of EPA and DHA, but the conversion rates are low $[16,17]$. Accordingly, the DHA intake in food is important.

As DHA is present in deep water fish such as salmon, mackerel, clupea, sardine, and tuna $[18,19]$, it was suggested that the effect was attributable to variations in the intake of DHA. The fish lipids derived from these diets prevent coronary artery disease, heart failure, and cardiac arrhythmias, for example, and lower the mortality rate from these CVDs [20, 21]. In addition, it has been found that the circulating concentrations of DHA and EPA were inversely related to CVD incidence [22].

It has been shown that several mechanisms account for the protective effects of EPA or/and DHA against CVD. For example, n-3 FAs in fish oils inhibit cardiac arrhythmias and decrease plasma triglycerides, but have little effect on low-density (LDL) or high-density (HDL) lipoprotein cholesterol levels [23]. n-3 FA may inhibit inflammation [24], and may prevent atherosclerosis and plaque rupture by an anti-inflammatory effect [25]. In older and hypertensive subjects, a high intake of fish oil may lower blood pressure [26]. In patients with Type 2 diabetes, moderate oral supplementation with DHA improved platelet function and oxidative stress [27]. The relations between polyunsaturated fatty acids (PUFAs) and CVD were investigated in 2837 US adults, and DHA was found to be inversely associated with CVD incidence [24]. DHA may have anti-thrombotic, antiatherogenic, anti-arrhythmic, and vasoprotective effects [28]. With regard to anti-thrombotic activity, DHA decreases platelet aggregation and blood viscosity and also affects clotting factors. In relation to anti-atherogenic activity, it reduces plasma triglycerides, inhibits the migration and growth of vascular smooth muscle cells (SMC), and inhibits the production of cytokines and adhesion molecules. The anti-arrhythmic activity results from effects on membrane ion channels, increases in VF threshold (HRV), alterations in membrane fluidity, and limitation of ischemic damage. Furthermore, it has been shown that DHA induces the expression of nitric oxide synthase (eNOS) and stimulates the production of nitric oxide in vascular endothelial cells [29]. It also prevents vascular inflammation and decreases monocyte adhesion induced by oxidized LDL (ox-LDL) in coronary endothelial cells [30].

It has been shown that DHA reduces endothelial cell injury, decreases an inflammatory marker, and prevents
CVD. In particular, lectin-like oxidized LDL receptor-1 (LOX-1) may contribute to vascular endothelial dysfunction and enhance atherosclerosis [31, 32]. However, DHA inhibited TNF- $\alpha$-induced gene expression related to endothelial dysfunction, including LOX-1 [33]. Furthermore, DHA inhibits induction of inflammation by controlling cell signal transduction and altering gene expression in the cells. It can inhibit tumor necrosis factor-alpha (TNF $\alpha)$-induced vascular cell adhesion molecule-1 (VCAM-1) expression by reducing the NF$\kappa \mathrm{B}$ signaling pathway [34]. Its vasoprotective effects indicate that it improves vascular endothelial cell function, modulates receptor-agonist interactions, reduces blood pressure, and reduces end-organ damage. These properties of DHA help to prevent circulatory disease and to regulate many metabolic functions. Free fatty acid receptor 4 (FFAR4) is activated by n-3 PUFAs such as ALA, EPA, and DHA [35]. With regard to the mode of action of DHA, FFAR4 is likely to be related to the function of DHA [36, 38]. However, neither the efficacy nor the mechanism of action of DHA in CVD prevention is completely understood. Endothelial cell-dependent contractions are reduced when the release of nitric oxide is impaired by oxidative stress, ageing, hypertension, and diabetes [39]. The aim of this paper was to review the effects of DHA on vascular endothelial cells and recent findings on their potential for the prevention of circulatory diseases.

\section{Dietary sources of DHA and its biosynthesis from alpha-linolenic acid}

DHA is an n-3 FA component of the phospholipids of animal cell membrane, including those of the skin and retina, and is present in high concentrations in human brain tissue. It can be synthesized from alpha-linolenic acid (ALA) in vivo, and is supplied directly to infants in maternal milk. ALA is a substrate for the synthesis of the long-chain fatty acids EPA and DHA, but the conversion rates are low $[40,41]$, with only $0.2 \%$ being converted to EPA and $0.05 \%$ to DHA [41]. Therefore, the DHA consumed in food is important. The conversion of ALA to EPA and DHA is catalyzed by elongase and a desaturase enzyme [40] (Fig. 1). The desaturase shares ALA with elongase and the conversion ratio is affected by the quantity of substrate. When n-6 PUFA is abundant, the amount converted to n-3 PUFA decreases. On the other hand, EPA can be converted to DHA or eicosanoids. Many eicosanoids induce inflammation. But there is much greater potential for inflammatory activity with n-6 than with n-3 PUFAs, which are less inflammatory [41]. For example, prostaglandins (PGs), thromboxanes (TXs), and leukotrienes are representative eicosanoids that enhance inflammation. Also, competition between n- 6 and n-3 FAs for metabolic enzymes influences the concentrations of 


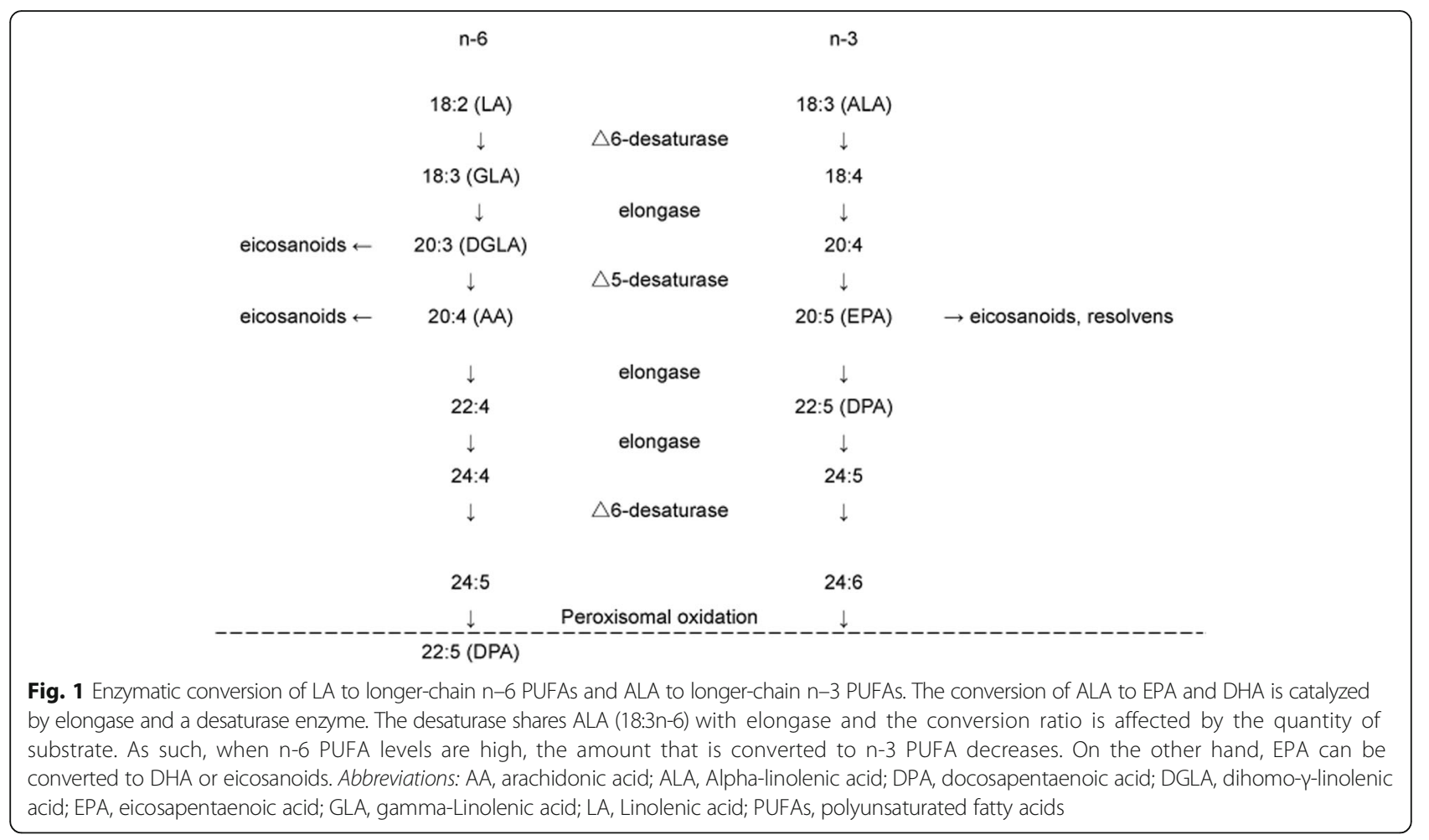

various eicosanoids, which might contribute to the prevention of CVD by PUFAs [42]. Table 1 shows the main dietary sources of EPA, docosapentaenoic acid (DPA), and DHA [43]. Generally, deep water fish such as tuna, salmon, mackerel, herring, and sardines have high contents of EPA and DHA. In particular, salmon, trout and herring contain the highest concentrations of DHA [19].

\section{Protective effects of DHA on vascular endothelial dysfunction in vitro}

Vascular endothelial dysfunction and cardiovascular disease

Vascular endothelium consists of a single layer of cells lying between the blood and smooth muscle cells of blood vessel walls, where they play an important role in the homeostasis of vascular function. Vascular endothelial cells control blood pressure (BP), vascular permeability, blood coagulation, arterial stiffness, and inflammation. In addition, endothelial cells have many receptors, binding proteins, and transporters that regulate cell growth, apoptosis, and cell migration. The health of endothelial cells, which is essential for normal vascular function, is maintained by the synthesis of several molecules, including nitric oxide (NO), PGI2, and angiotensin II (AII) in response to physical and chemical stimuli [44-46]. For example, endothelial cells produce AII by the action of angiotensin converting enzyme (ACE), which is located in the cell membrane. The AII then stimulates the contraction of vascular smooth muscle cells to increase BP.
Endothelial cells additionally release endothelin-1 (ET-1), which also causes smooth muscle to contract. Endothelial cells also regulate the production of $\mathrm{NO}$, endotheliumderived hyperpolarizing factor (EDHF), and eicosanoids. The LOX-1 is a scavenger receptor that mediates the incorporation of ox-LDL into vascular cells. LOX-1 expression is recognized in atherosclerotic lesions and may contribute to vascular endothelial cell dysfunction and be an important risk factor for atherosclerosis [31, 32]. On the other hand, in certain diseases endothelial cells have the potential to increase the production of free radicals and thereby to promote vascular disorders. The balance between constriction and relaxation breaks down when the integrity and function of vessels are disturbed. Such dysfunctions can be caused by hypercholesterolemia, hypertension, diabetes, and smoking. Consequently, defective endothelial cell function is associated with a high risk of cardiovascular events [47] and leads to CVDs such as hypertension [48], atherosclerosis [49], and stroke [50].

\section{Mechanisms by which DHA prevents endothelial dysfunction}

Studies in vitro with cultured cells have shown that there are several biomarkers of endothelial dysfunction. Vascular endothelial cell dysfunction is exacerbated when the release of $\mathrm{NO}$ is impaired by oxidative stress, ageing, hypertension, and diabetes [39]. In particular, NO plays a key role in the prevention of CAD exerted by endothelial cells. Thus, endothelial cells play important roles in 
Table 1 Major dietary sources of $\mathrm{DHA}^{\mathrm{a}}$

\begin{tabular}{|c|c|c|c|c|c|c|c|}
\hline & & & & & & & $(\mathrm{mg} / 100 \mathrm{~g})$ \\
\hline & EPA & DPA & $\mathrm{DHA}$ & & EPA & DPA & $\mathrm{DHA}$ \\
\hline Anchovy & 763 & 41 & 1292 & Tuna, light (skipjack) & 91 & 17 & 237 \\
\hline Herring, Atlantic & 909 & 71 & 1105 & Snapper & 48 & 22 & 273 \\
\hline Salmon, farmed & 862 & 393 & 1104 & Flounder and sole & 168 & 34 & 132 \\
\hline Salmon wild & 411 & 368 & 1429 & Clams & 138 & 104 & 146 \\
\hline Mackerel, Atlantic & 504 & 106 & 699 & Grouper & 35 & 17 & 213 \\
\hline Bluefish & 323 & 79 & 665 & Halibut & 80 & 20 & 155 \\
\hline Sardines, Atlantic & 473 & 0 & 509 & Lobster & 117 & 6 & 78 \\
\hline Trout & 259 & 235 & 677 & Scallops & 72 & 5 & 104 \\
\hline Golden bass (tilefish) & 172 & 143 & 733 & Blue crab & 101 & 9 & 67 \\
\hline Swordfish & 127 & 168 & 772 & Cod, Paciflc & 42 & 5 & 118 \\
\hline Tuna, white (albacore) & 233 & 18 & 629 & Shrimp & 50 & 5 & 52 \\
\hline Mussels & 276 & 44 & 506 & Catfish, farmed & 20 & 18 & 69 \\
\hline Striped bass & 169 & 0 & 585 & Eggs & 0 & 7 & 58 \\
\hline Shark & 258 & 89 & 431 & Chicken breast & 10 & 10 & 20 \\
\hline Pollock, Atlantic & 91 & 28 & 451 & Beef & 2 & 4 & 1 \\
\hline Oysters, wild & 274 & 16 & 210 & Pork & 0 & 10 & 2 \\
\hline King mackerel & 174 & 22 & 227 & & & & \\
\hline
\end{tabular}

Abbreviations: DHA docosahexaenoic acid, EPA eicosapentaenoic acis, DPA docosapentaenoic acid

${ }^{\text {a }}$ Adapted from reference [43] Mozaffarian and Wu, 2012

vascular function and in the maintenance of normal homeostasis via the production of biochemical mediators. NO from endothelial cells is generated by eNOS (Fig. 2). Vascular endothelial cells generate vasoactive molecules such as vasorelaxants and vasoconstrictors [51]. NO, PGI2, and EDHF regulate vascular relaxation, and AII and ET-1 stimulate vasoconstriction (Fig. 3).

The consumption of fish or fish oil influences the expression of various vasoactive molecules and $\mathrm{NO}$ production by eNOS gene expression in endothelial cells. Furthermore, DHA induces endothelium-dependent NO-mediated relaxation in the coronary artery. The cells are essential for the transport of metabolites, the control of vascular tone, angiogenesis, and the regulation of hemostasis and blood coagulation [52]. In cultured human coronary artery endothelial cells, DHA enhanced NO production and the activity of eNOS. In addition, it enhanced the expression of eNOS and phospho-eNOS. Specifically, DHA stimulated eNOS and Akt activity, enhanced HSP90 expression, and induced NO bioavailability in response to Akt kinase activation [53]. Earlier studies had demonstrated that DHA prevented TNF $\alpha$-induced VCAM- 1 and monocytic cell adhesion in human endothelial cells [34]. Also, DHA decreased TNF- $\alpha$-enhanced VCAM-1 expression through inhibition of the NF- $\mathrm{kB}$ signaling pathway and AP-1 activation in human aortic endothelial cells [34]. Expression of VCAM- 1 and ICAM- 1 on the cell surface of human endothelial cells was determined by a cell-surface enzyme-linked immunosorbent assay. In addition, protein expressions of VCAM-1 and ICAM-1 were determined using Western blot analysis [34]. Furthermore, DHA inhibited TNF- $\alpha$ induced intercellular adhesion molecule 1 (ICAM-1) expression and promoter activity. Synchronously, DHA attenuated TNF- $\alpha$-induced inhibitory kappa B (ІкB) kinase (IKK) phosphorylation and degradation, and p65 nuclear translocation [54]. These effects of DHA were related to Nrf2-mediated HO-1 expression and inhibition of the IKK/ NF- $\mathrm{KB}$ signaling pathway. Furthermore, DHA inhibited TNF- $\alpha$-induced phosphorylation of extracellular signalregulated kinase (ERK), expression of the early growth response gene, ICAM-1, and monocyte cell line HL-60 cell adhesion [55]. DHA may contribute to the inhibition of inflammation induced by TNF- $\alpha$, and consequently may reduce the risk of atherosclerosis as a consequence of endothelial dysfunction. We recently demonstrated that DHA prevented TNF- $\alpha$-stimulated gene expression related to dysfunction of human endothelial cells by PCR method, including plasminogen activator inhibitor 1 (PAI-1), LOX1 , and the thromboxane $\mathrm{A} 2$ receptor (TXA2R) [33]. It also reversed the TNF- $\alpha$-mediated decrease of eNOS gene expression. FFAR4 is a G protein-coupled receptor (GPCR) that is activated by n-3 PUFAs such as ALA, EPA, and DHA [35]. With regard to the mode of action of DHA, transfection with small interfering free fatty acid receptors 4 (FFAR4) blocked DHA-mediated inhibition of TNF- $\alpha$ enhanced ICAM-1 expression and cell adhesion of HL-60. 


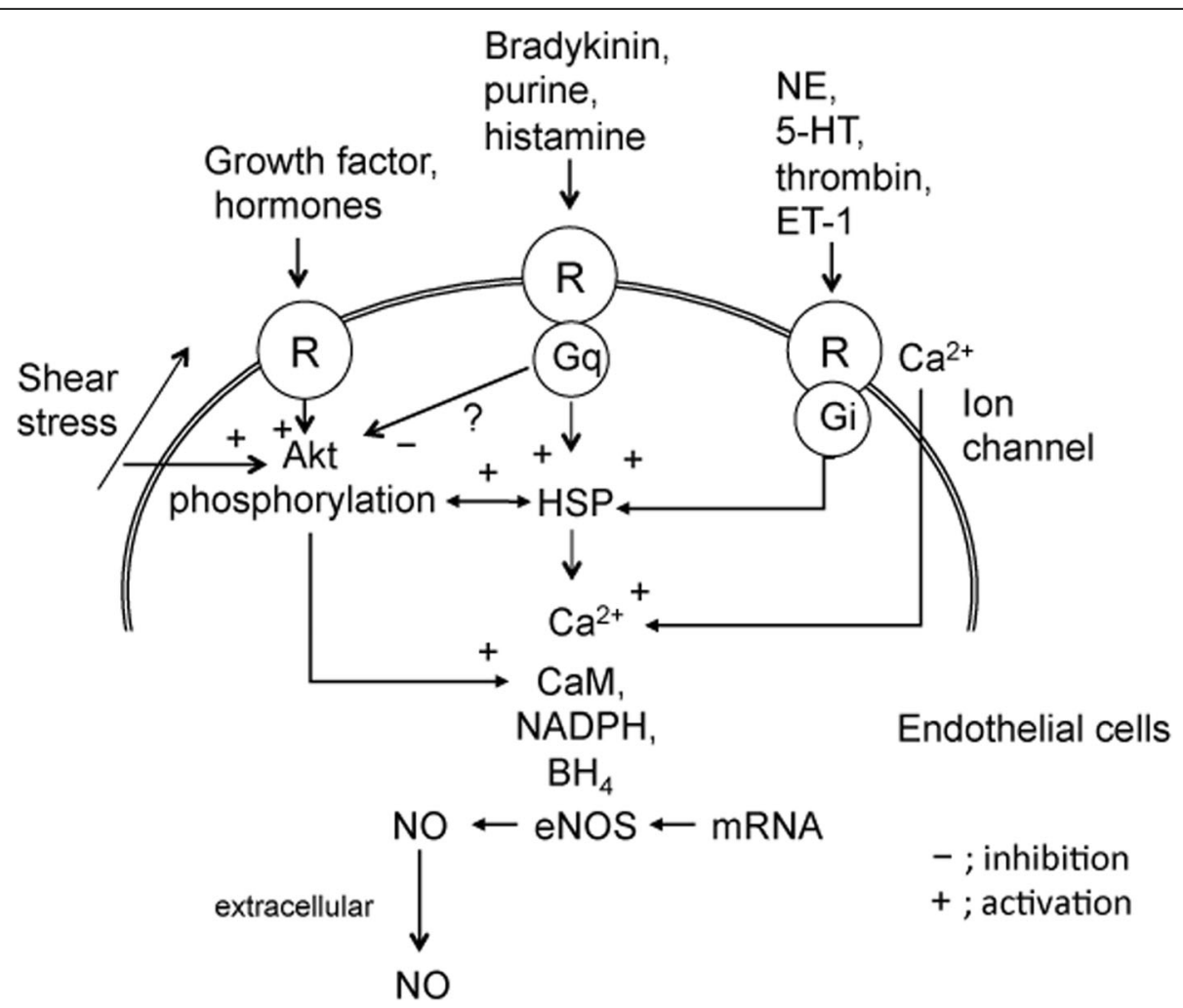

Fig. 2 A possible mechanism of nitric oxide production in endothelial cells. Nitric oxide is released through enzymatic conversion of $\mathrm{L}$-arginine by eNOS. eNOS transcription is induced by growth factors and hormones, whereas eNOS enzyme activity requires calcium, calmodulin, NADPH and BH4. The activity of eNOS is regulated by complex formation with these proteins in microdomains of endothelial cells. The L-arginine metabolite, ADMA, reduces production of nitric oxide by competitive binding to eNOS. Abbreviations: R, receptor; HSP, heat shock protein; NE; 5-HT, serotonin (5-hydroxytryptamine); ET-1, endothelin-1; CaM, calmodulin; NADPH, nicotinamide adenine dinucleotide phosphate; BH4, 5,6,7,8-tetra-hydrobiopterine; NO, nitric oxide; eNOS, nitric oxide synthase

This result indicated that FFAR4 is likely to be associated with the function of DHA. DHA stimulated protein phosphatase 2A (PP2A) enzyme activity and decreased vascular endothelial growth factor (VEGF)-induced phosphorylation of ERK1/2 and eNOS. Moreover, DHA and the FFAR4 agonist GW9508 have been shown to inhibit VEGFinduced cell migration [36]. In this study, human endothelial cells were used as the experimental model, and Western blotting, and assays for MTT, phosphatase activity, and wound-healing were used to explore the effects of DHA on cell migration [36]. The effects of DHA on wound repair and angiogenesis are at least partly owing to a reduction of cell migration. Together, these results indicate that DHA can decrease VEGF-induced cell migration by FFAR4 and via the PP2A/ERK1/2/eNOS signaling pathway [36] (Fig. 4). The activation of FFA4 by FAs induces incretin production in the gut [37] and controls insulin resistance [38] and antiinflammatory effects in macrophages [56]. These data suggest that stimulation of FFAR4 may enhance metabolic homeostasis.

Macrophages also have FFAR4 signaling pathways that can be affected by anti-inflammatory molecules [57]
(Fig. 5). A few reports have provided evidence that TAB1 is controlled by FFAR4 stimulation. For example, lipopolysaccharide (LPS) and TNF- $\alpha$ are strong enhancers of inflammatory processes following activation of the toll-like receptor 4 (TLR4) and TNF receptors (TNFRs). In addition, they activate the TAK1 complex of transforming growth factor beta-activated kinase 1 (TAK1) and TGF- $\beta$ activated kinase 1 (TAB1) binding protein. Activation of either TLR4 or TNFR causes TAK1 to interact with its binding protein TAB1, which activates the TAK1 complex. Activated TAK1 phosphorylates MAPK kinases 4 (MKK4) and enhances the phosphorylation of Jun-N-terminal kinase (JNK). TAK1 also enhances the phosphorylation of IKK- $\beta$ and NF- $\mathrm{kB}$. NF$\kappa \mathrm{B}$ and phospho-JNK are augmented causing an elevation in the expression of inflammatory mediators such as TNF- $\alpha$, interleukin-6 (IL-6), IL-1 $\beta$, cyclooxygenase 2 (COX) 2, monocyte chemoattractant protein-1 (MCP-1), and inducible NOS (iNOS). But FFAR4 inhibits the separation of TAB1 and blocks the potential for interaction with TAK1. On the other hand, activation of FFAR4 can lead to $\beta$-arrestin-2 enhancement and inhibit its interaction with 


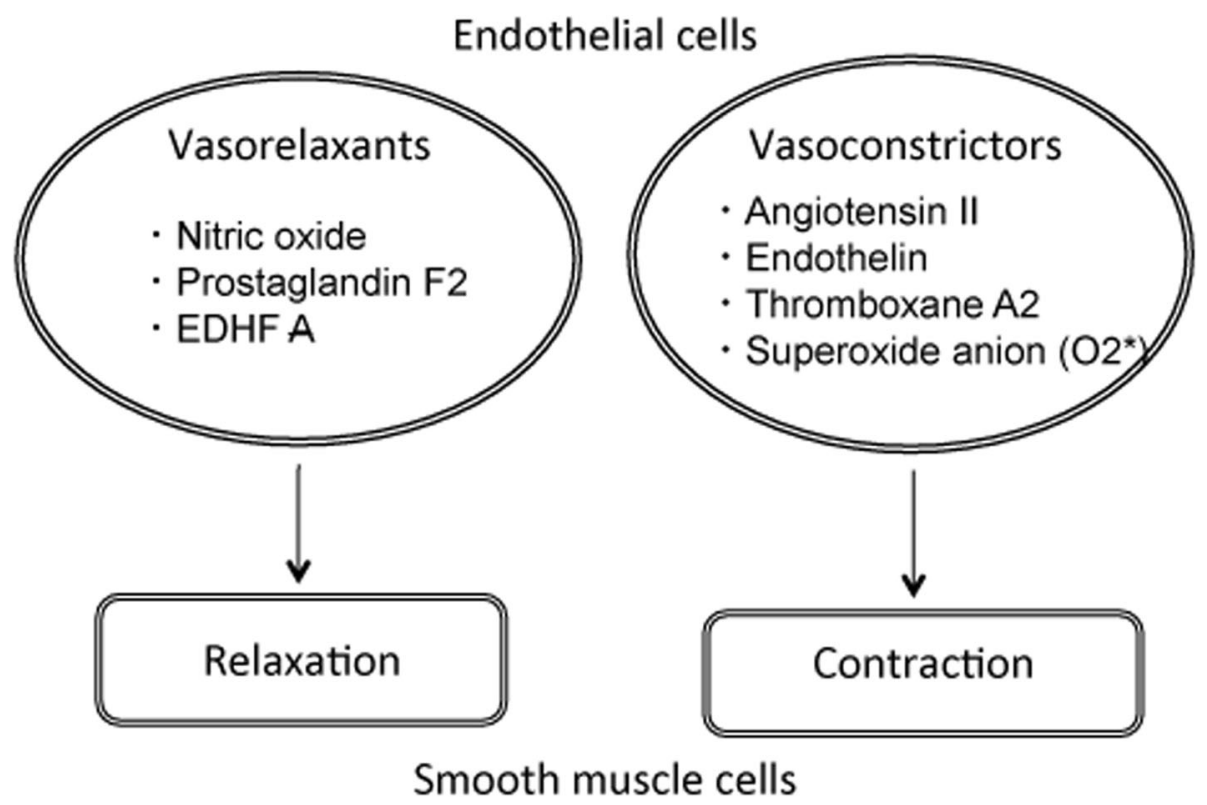

Fig. 3 Regulation of relaxation and contraction of smooth muscle cells by vasoactive compounds. Vasoconstriction and vasorelaxation of vascular endothelial cells are controlled by vasoactive molecules such as NO, PGI2, and EDHF that act as vasorelaxants, or vasoconstrictors, which include All, ET-1, TXA2 and superoxide anion. Abbreviations: All, angiotensin II; ET-1, endothelin; EDHF, endothelium-derived hyperpolarizing factor. NO, nitric oxide; $P G 12$, prostaglandin F2; TXA2, thromboxane A2. Abbreviations: All, angiotensin II; ET-1, endothelin; EDHF, endothelium-derived hyperpolarizing factor. NO, nitric oxide; PGI2, prostaglandin F2; TXA2, thromboxane A2

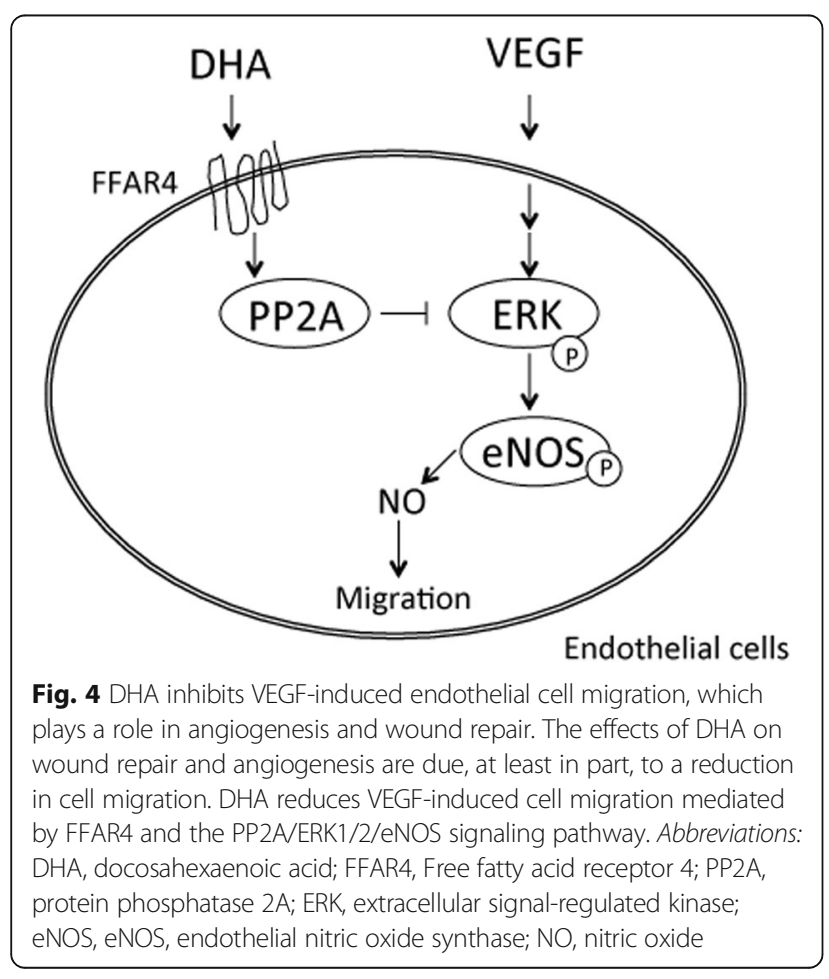

TAK1. These actions of FFAR4 inhibit downstream activation of NF- $\mathrm{kB}$ and JNK to induce anti-inflammatory effects. These data demonstrate that DHA tends to be more effective in attenuating the effects of compounds in the inflammatory cascade in endothelial cells [58]. FFA4 may also mediate the anti-inflammatory and insulin-sensitizing effects of omega 3 fatty acids [59]. Recently, it was shown that FFAR4 assumed an important role in the efficacy of n3FA in heart failure [60].

Taken together, DHA affects angiogenesis and wound repair owing to its potential to attenuate cell migration. Furthermore, DHA prevents LPS-induced VCAM-1 and ICAM-1 expression and the adhesion of THP-1 cells to human aortic endothelial cells [61]. DHA inhibited the translocation of TNFR-associated factor 6 (TRAF6) and the phosphorylation of TAK1, $\mathrm{p} 38$, and $\mathrm{I} \mathrm{B} \mathrm{B} \alpha$. These signaling pathways in which DHA can exert effects may be potential targets for the prevention of atherosclerosis.

\section{Effects of DHA on cardiovascular disease risk factors: Studies in vivo}

DHA lowers plasma triglycerides and inflammation, and has been shown to suppress platelet aggregation. Table 2 shows the effects of DHA on risk factors for cardiovascular disease $[43,62]$. 


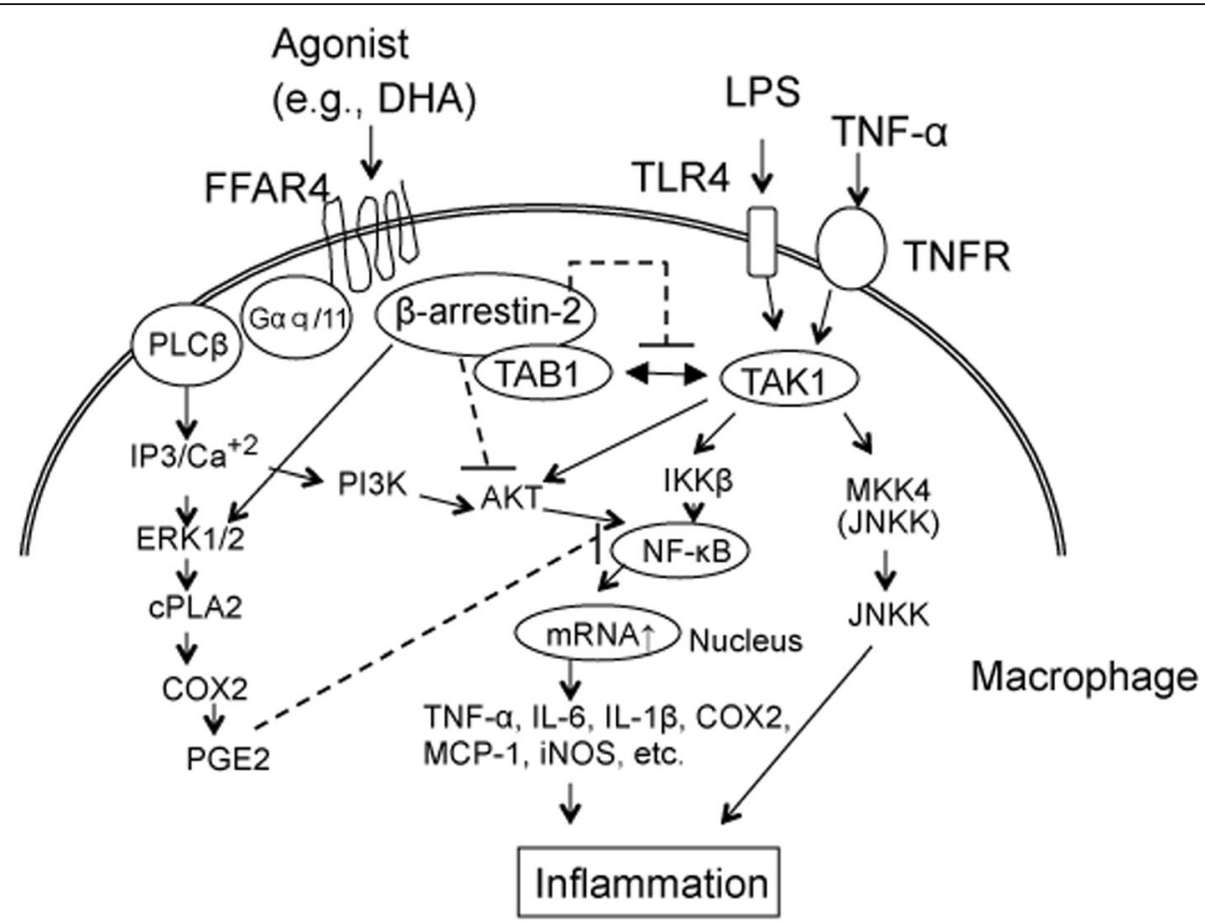

Fig. 5 Anti-inflammatory FFA4 signaling pathways in macrophages and mechanisms of action of DHA. Macrophages have FFAR4 signaling pathways that can be affected by anti-inflammatory molecules. LPS and TNF-a induce inflammatory processes following activation of TLR4 and TNFR, which subsequently activate the TAK1 complex of TAK1 and the TAB1 binding protein. Activated TAK1 phosphorylates MKK4 and induces JNK phosphorylation. TAK1 also induces the phosphorylation of IKK- $\beta$ and NF-KB. NF-KB and phospho-JNK enhance mRNA expression of inflammatory mediators such as TNF-a, IL-6, IL-1 $\beta$, COX 2, MCP-1 and iNOS. In contrast, FFAR4 together with DHA inhibits TAB1 dissociation and blocks potential TAK1 interactions. Activation of FFAR4 can be induced by $\beta$-arrestin-2 enhancement to inhibit its interaction with TAK1. These actions of FFAR4 block downstream activation of NF-KB and JNK to induce anti-inflammatory effects. Abbreviations: DHA, docosahexaenoic acid; FFAR4, Free fatty acid receptor 4; ERK 1/2, extracellular signal-regulated kinase 1/2; COX2, cyclooxygenase 2; TAB1, TGF- $\beta$ activated kinase 1; TAK1, Transforming growth factor beta-activated kinase 1; TLR4, toll-like receptor 4; LPS, lipopolysaccharide; TNFa, tumor necrosis factor-alpha; TNFR, tumor necrosis factor receptor; MKK4; JNKK, Jun-N-terminal kinase kinase; IL-6, interleukin-6; IL$1 \beta$, interleukin-1 beta; MCP-1, monocyte chemoattractant protein-1; iNOS, inducible nitric oxide synthase

\section{Effect of DHA on plasma triglycerides}

As shown in Table 2, a decrease in plasma triglycerides is a common effect of DHA [63]. For example, after fish oil supplementation a decrease in plasma triglycerides and increases in platelet phospholipid arachidonic acid and plasma HDL were observed [64]. Simultaneous increases in plasma HDL, platelet phospholipid EPA, and DHA levels were observed after fish-oil supplementation. Reduced hepatic VLDL synthesis, decreased hepatic enzyme activity for triglyceride synthesis, and enhanced hepatic synthesis of phospholipids contributed to these effects $[65,66]$.

\section{Inhibitory effects of DHA on inflammation and CVD}

One of the biological effects of n-3 PUFA is to alter the course of inflammatory stimulation. However, in the amounts normally present in the diet it is not known whether DHA reduces inflammation and confers clinical benefit. In several studies, it was shown that supplementation of n-3PUFA decreased the actions of multiple eicosanoids $[24,67]$. Furthermore, DHA decreased inflammatory markers such as interleukin-1 beta (IL-1 $\beta$ ) and TNF $\alpha$, IL-6. The potential for the use of DHA to treat diseases associated with inflammation has been demonstrated $[68,69]$. During the onset of CVD, the anti-inflammatory effects of n-3 PUFAs may mediate their protective activities against atherosclerosis and plaque rupture [17]. A recent study described effects of $\omega-3$ fatty acids on toll-like receptor 4 and NF- $\kappa B$ p56 in the lung during severe acute pancreatitis in rats [70]. DHA reduced IL- $1 \beta$-induced VCAM- 1 , COX2, and VEGFR2 expressions in human intestinal microvascular endothelial cells. Furthermore, it prevented IL-1 $\beta$ enhanced production of PGE2 and LTB4 in intestinal microvascular endothelial cells. Also, in rats with colitis fish oil rich in EPA and DHA inhibited the production of PGE2 and LTB4 in the colon, and VCAM-1 and VEGFR2 in endothelial cells [71]. It was shown that PUFA exerted these effects by activating a critical modulator of pro-inflammatory cytokines, TLR4 [73]. By contrast, DHA also suppressed inflammation by controlling the expression of COX2 through activation of FFA4 in macrophages [72]. 
Table 2 Evidence for cardiovascular effects of EPA, DHA and DPA in human sutdies

\begin{tabular}{|c|c|c|c|}
\hline & EPA & $\mathrm{DHA}$ & DPA \\
\hline \multicolumn{4}{|l|}{ Physiologic risk factors } \\
\hline \multirow[t]{3}{*}{ Lipids } & $\downarrow$ TG levels & $\downarrow$ TG levels & - \\
\hline & $\downarrow \mathrm{HDL}_{3}$ cholesterol $^{2}$ & $\uparrow$ LDL particle size & \\
\hline & & $\uparrow \mathrm{HDL}_{2}$ cholesterol & \\
\hline \multirow{4}{*}{$\begin{array}{l}\text { Vascular and cardiac } \\
\text { hemodynamics }\end{array}$} & Minimal BP effects & $\downarrow \mathrm{BP}$ & - \\
\hline & ? Heart rate effects & $\downarrow$ Heart rate & \\
\hline & $\uparrow$ Cardiac diastolic filling ${ }^{2}$ & $\uparrow$ Cardiac diastolic filling ${ }^{2}$ & \\
\hline & $\uparrow$ Arterial compliance $^{2}$ & $\uparrow$ Arterial compliance $^{2}$ & \\
\hline Endothelial function & No clear effects ${ }^{2}$ & No clear effects ${ }^{2}$ & - \\
\hline $\begin{array}{l}\text { Inflammation and } \\
\text { oxidative }\end{array}$ & $\downarrow$ Inflammation, mixed & $\downarrow$ Inflammation, mixed & $\downarrow$ Inflammation, mixed \\
\hline \multirow[t]{2}{*}{ stress } & results $^{2}$ & results $^{2}$ & results $^{2,3}$ \\
\hline & $\downarrow$ Oxidative stress, mixed results ${ }^{2}$ & $\downarrow$ Oxidative stress, mixed results ${ }^{2}$ & \\
\hline \multirow[t]{2}{*}{$\begin{array}{l}\text { Thrombosis and } \\
\text { coagulation }\end{array}$} & $\begin{array}{l}\downarrow \text { Collagen-stimulated platelet } \\
\text { aggregation }^{2}\end{array}$ & $\begin{array}{l}\downarrow \text { Collagen-stimulated platelet } \\
\text { aggregation }^{2}\end{array}$ & $\begin{array}{l}\downarrow \text { Collagen-stimulated platelet } \\
\text { aggregation }{ }^{2}\end{array}$ \\
\hline & $\begin{array}{l}\text { Otherwise minimal effects on thrombosis } \\
\text { or coagulation }\end{array}$ & $\begin{array}{l}\text { Otherwise minimal effects on thrombosis } \\
\text { or coagulation }\end{array}$ & \\
\hline
\end{tabular}

1. BP blood pressure, $C H D$ Coronary heart disease, DPA docosapentaenoic, - minimal data available for direct assessment.

2. Base on a single study or few studies. 3. Observation studies only.

Abbreviations: DHA docosahexaenoic acid, EPA eicosapentaenoic acid, DPA docosapentaenoic acid, TG Triglycerid, BP blood pressure, HDL high-density lipoprotein, $L D L$ low-density lipoprotein, NO nitric oxide.

Adapted from reference [43] Mozaffarian and Wu, 2012

\section{Preventive effects on CVD of n-3 PUFA and DHA in studies in vivo}

CVDs are a group of disorders of the heart and blood vessels, including coronary heart disease, cerebrovascular disease, and peripheral arterial disease. As shown in Table 3, in several meta-analyses of population studies [73-78] and randomised controlled trials [79-85], fish consumption has been shown to prevent coronary heart disease, stroke, and total mortality after stroke in humans [62]. Arteriosclerosis and hypertension are strong risk factors for CVD. Therefore, these effects of DHA could lead to prevention of CVD.

\section{Arteriosclerosis}

Arteriosclerosis is a major cause of heart disorders and cerebrovascular disease. Epidemiologic studies have shown that Japanese men have less atherosclerosis than Caucasian men living in the USA [86]. This study showed that intima-media thickness (IMT) of the carotid artery and coronary artery calcification $(\mathrm{CAC})$ were significantly less in Japanese. Namely, a population-based study in 306 white and 281 Japanese-American men aged 40-49 years was conducted to investigate the IMT of the carotid artery. IMT was associated with the plasma concentration of n-3 PUFAs in Japanese men, but a similar association was not observed for coronary artery disease (CAD). Previous reports had found that an extremely high intake of n-3 PUFAs inhibits atherosclerosis [87]. On the other hand, another report showed that DHA prevented chronic intermittent hypoxia-induced atherosclerosis but did not improve atherosclerosis in control apolipoprotein- $\mathrm{E}$ deficient mice [88]. In the aorta, expression of matrix metalloproteinase-2 (MMP-2) was found to be decreased by DHA. In 160 Japanese patients with CAD [54] the serum level of DHA was related to endothelial function as evaluated by flow-mediated dilation (FMD) in patients with CAD. These results suggest that a low serum level of DHA may be a biomarker of endothelial dysfunction, and that DHA may prevent chronic intermittent hypoxia-induced atherosclerosis [89].

\section{Hypertension}

The active components in fish oil that underlie its antihypertensive effect are thought to be EPA and DHA. DHA and EPA have been shown to decrease BP in subjects with essential hypertension [90]. Namely, in men and women with mild essential hypertension $(n=156)$, the effects of $6 \mathrm{~g}$ per day of 85\% EPA and DHA were examined in a 10-week dietary study. EPA and DHA decreased the BP in essential hypertension [92]. An international cross-sectional epidemiologic study of 4680 subjects in China, Japan, UK, and USA found that dietary n-3 LC-PUFAs were inversely associated with BP [91]. The results of this study indicate that foods containing n-3 PUFA may contribute to the prevention and 
Table 3 Studies examining the effect of $n-3$ fatty acids as fish oils on CHD, stroke and total mortality

\begin{tabular}{ll}
\hline Authors & Results of meta-analyses of population studies \\
\hline Wang et al. (2006) [76] & $\downarrow$ all-cause mortality; cardiac and sudden death \\
Bucher et al. (2002) [73] & $\downarrow$ total mortality; cardiac and sudden death \\
He et al. (2004) [77] & $\downarrow$ CHD mortality \\
Whelton et al. (2004) [75] & $\downarrow$ fatal and total CHD \\
He et al. (2004) [77] & $\downarrow$ stroke, particularly ischaemic stroke \\
Xun et al. (2012) [78] & $\downarrow$ stroke, particularly ischaemic stroke \\
Authors & Results of randomised controlled trials \\
Burr et al. (1989) [79] & $\downarrow$ all-cause mortality in post-Ml patients \\
Valagussa et al. (1999) [80] & $\downarrow$ total and cardiovascular mortality; sudden \\
Tavazzi et al. (2008) [82] & death in post-Ml patients \\
& $\downarrow$ total mortality and hospital admission for CVD \\
in heart failure patients coronary events in patients \\
wokoyama et al. (2007) (81] hypercholesterolaemia \\
Bosch et al. (2012) [83] & $\rightleftarrows$ cardiovascular events in patients at high risk of \\
Mozaffarian et al. (2012) [84] & CVD and impaired glucose or diabetes \\
& $\rightleftarrows$ post-operative atrial fibrillation in patients undergoing \\
\end{tabular}

Abbreviations: CHD coronary heart disease, CVD cardiovascular disease.

Adapted from reference [62] Mori et al. 2014

control of adverse BP levels. Furthermore, in a recent intervention study it was determined that dietary intakes of DHA and EPA significantly reduced BP [92]. Results from 70 randomized controlled trials demonstrated that consumption of $\geqq 2$ g EPA daily plus DHA reduces systolic and diastolic BP. DHA reduced ambulatory systolic and diastolic BP and heart rate (HR) in 56 mildly hyperlipidemic obese men [93]. In the study design, 59 subjects were randomly assigned to consume $4 \mathrm{~g}$ EPA, DHA, or olive oil/day for 6 weeks. DHA intake reduced systolic and diastolic BP and heart rate (HR), whereas EPA had no significant effect on either BP or HR. These results suggested that DHA, but not EPA, may decrease $\mathrm{BP}$ and $\mathrm{HR}$ in men. In a more recent meta-analysis of randomized controlled trials, EPA plus DHA was found to reduce both systolic and diastolic BP relative to a placebo [92]. BP was reduced by EPA plus DHA (2 g daily) in both normotensive and hypertensive subjects, and the effect was particularly strong in those with untreated hypertension. Lower doses of EPA plus DHA (between 1 and $2 \mathrm{~g} /$ day) might reduce systolic BP but not diastolic BP. In another study, the effects of DHA and EPA were investigated in relation to $\mathrm{BP}$, serum lipids, and glycemic control in patients with type 2 diabetes [94]. Study design were 59 subjects were randomly assigned to consume 4 g EPA, DHA, or olive oil/day for 6 weeks. DHA and EPA had similar beneficial effects on lipids, but inverse effects on short-term glycemic management and $\mathrm{BP}$ control in hypertensive type 2 diabetics. This result indicated that the effect of DHA on hypertension necessitates long-term evaluation. Furthermore, the lowering effects of DHA on BP, as well as its effects on endothelial and cardiac function, were confirmed in meta-analyses. DHA may influence both BP and heart conditions, as assessed by HR and electrocardiogram (ECG), and may control adrenergic function [95].

In spontaneously hypertensive rats (SHR), the antihypertensive effect of intake of DHA, EPA, and gammaLinolenic acid (GLA) was compared with that in normotensive Wistar Kyoto rats (WKY) [96]. SHR rats and WKY rats were fed for 10 weeks a diet containing either $5.65 \mathrm{~g} / \mathrm{kg}$ GLA, $6.39 \mathrm{~g} / \mathrm{kg}$ EPA, or $4.94 \mathrm{~g} / \mathrm{kg}$ DHA. In SHR, dietary supplementation with DHA significantly decreased BP, enhanced total antioxidant status, and reduced the speed of platelet aggregation. These results indicated that DHA not only reduces $\mathrm{BP}$ but also improves oxidation status and reduces platelet aggregation in hypertensive rats.

A recent randomized controlled trial indicated that daily doses of EPA plus DHA as low as $0.7 \mathrm{~g}$ achieve clinically useful BP reductions, and might be associated with lower CVD risk [97]. In this double-blind placebocontrolled RCT, normal men and women $(n=312)$ were given fish oil containing EPA plus 0.7 or $1.8 \mathrm{~g}$ of DHA per day for eight weeks.

\section{Coronary artery disease}

Many epidemiologic studies have observed an inverse association between n-3 PUFA intake and CVD. A high 
intake of n-3 PUFAs in fish or fish oil supplements reduced all-cause mortality, including mortality from heart disease and sudden death [76]. Several studies have recorded an inverse relation between n-3 LC-PUFAs and coronary heart disease (CHD) [73, 98, 99]. A metaanalysis of seventeen cohort studies conducted by [99] searched the databases of PubMed and the Institute of Science Index from to 2010. Data from relevant studies were retrieved from 315,812 participants collected over nine to 15 years. In the pooled data, a dose-response analysis showed that every additional $15 \mathrm{~g}$ /day of fish intake decreased the risk of CHD mortality by $6 \%$. This study also demonstrated that both low and moderate fish intake decrease CHD mortality. Furthermore, in 517 patients in urban Japan who were on maintenance hemodialysis, alterations in their serum PUFA profiles during therapy were associated with CVD risk [100].

The blood levels of n-3 PUFAs can vary depending on a person's location and dietary habits, and these differences may influence the preventive effects conferred by DHA. These reports and other studies concluded that enhanced seafood intake is beneficial and may contribute to the prevention of CVD [83-85]. Other recent research in the patients with hypertriglyceridemia and low HDL cholesterol (HDL-C) showed that the combination of a statin and n-3 FFA was effective for the treatment of coronary artery disease [101].

The effects of DHA on endothelial cell function in patients with CAD have been investigated. The results demonstrated a relation between the circulating concentration of DHA and CAD in Japanese patients; serum DHA was also associated with endothelial function as evaluated by FMD [96]. Evidence that DHA may inhibit disorders of endothelial functional induced by high-fat diets was obtained from studies in 20 healthy humans by Fahs et al. (2010) [102]. Namely, brachial artery FMD, forearm blood flow (FBF), total hyperemia, central and peripheral BP, and central artery stiffness were investigated in 10 healthy men and 10 healthy women after a high-fat diet supplemented with either a placebo or approximately $1 \mathrm{~g}$ EPA and DHA. On the other hand, treatment with DHA (2 g/day) enhanced modified brachial artery blood flow and conductance during exercise in humans. Thus, high concentrations of DHA may contribute to the prevention of endothelial dysfunction. These effects of DHA may mitigate CVD risk and exercise intolerance due to heart failure by preventing endothelial dysfunction [103].

\section{Cerebrovascular disease (stroke)}

Cerebrovascular disease, in particular stroke, is a severe life-threatening condition that occurs when the blood flow to part of the brain is interrupted. Several studies have investigated whether neuroprotection and long- term survival are enhanced by fish oil and DHA. Transient global cerebral ischemia-induced retrograde amnesia was reversed by fish oil [104], indicating that intake of fish oil ameliorates cerebral infarction. Fish oil might be therapeutic to neural dysfunction associated with learning and memory defects after cerebral ischemia. In addition, DHA had a protective effect on neurological disorders, such as neuronal cell death induced by middle cerebral artery occlusion (MCAO), in Sprague-Dawley (SD) rats [105]. DHA treatment reduced tissue loss and total and cortical infarct volumes compared to those in a saline-treated group. With regard to the mechanism, the inflammatory reaction of cells plays an important role in cerebral ischemic brain injury, and anti-inflammatory treatment of stroke is beneficial. In other words, dietary DHA has anti-inflammatory and neuroprotective effects against ischemic stroke. For example, in a rat model of permanent cerebral ischemia, DHA induced a neuroprotective effect against ischemia by decreasing brain infarction, edema, and disruption of the blood-brain barrier [106]. In this study, the results of Western blot, enzymatic assay, quantitative PCR, and flow cytometric analysis revealed that DHA decreased microglia activation, leukocyte infiltration, pro-inflammatory cytokine induction, and leukocyte activation after cerebral ischemia. Namely, DHA inhibited anti-inflammatory events, such as macrophages/microglia activation, leukocyte infiltration, pro-inflammatory cytokine expression, and leukocyte activation after cerebral ischemia.

A low serum n-3 PUFA/n-6 PUFA ratio predicted neurological deterioration in Japanese patients with acute ischemic stroke [107]. Furthermore, disease of cerebral small vessel (SVDs) is associated with stroke or diminished cognitive dysfunction. A study of 220 patients with cerebral infarction indicated that reduction of the percentage EPA, DHA, and n-3-PUFAs was related to the presence of cerebral micro-bleeds, highgrade white matter changes, and high-grade perivascular spaces, but not asymptomatic lacunar infarctions [108]. In addition, SVD scores were negatively correlated with the proportion of EPA, DHA and n-3-PUFAs. These results suggest that reduction of the level of n-3-PUFA in blood may induce small vessel disease in the brain in acute ischemic stroke patients.

DHA has also been found to protect neuronal cells after global cerebral ischemia reperfusion. In a rat vascular occlusion model, DHA inhibited hippocampal neuronal cell death [109] by decreasing Bax expression and increasing $\mathrm{Bcl} 2$ expression. These results suggest that DHA prevented ischemic stress-induced neuronal cell death. DHA has several other functions besides neuroprotection in cerebrovascular disorders by way of effects on neuronal excitation [110], memory [111], and photoreceptors [112, 114]. For example, there is evidence that it increases neuroprotectin 
D1 (NPD1) and may prevent cerebrovascular disease including ischemic stroke $[113,114]$.

\section{Conclusion}

In this review, the relation between the protective effects of fish oil fatty acids such as DHA and CVD is discussed. Many studies have shown that DHA has an important role in the function of vascular endothelial cells. During regular consumption of n-3 PUFAs, DHA has the potential to decrease endothelial dysfunction and prevent CVD through effects on endothelial metabolism, inflammation, thrombosis, and arrhythmia. Thus, dietary DHA prevents endothelial dysfunction and regulates vascular health. Intake of foods rich in DHA such as fish has the potential to make a significant contribution to the prevention of CVD.

\begin{abstract}
Abbreviations
ACE: angiotensin converting enzyme; ALA: Alpha-linolenic acid; BP: blood pressure; CVD: cardiovascular disease; DHA: docosahexaenoic acid; EDHF: endothelium-derived hyperpolarizing factor; eNOS: nitric oxide synthase; EPA: eicosapentaenoic acid; ET-1: endothelin-1; FFAR4: Free fatty acid receptor 4; HDL: high-density lipoprotein; ICAM-1: intercellular adhesion molecule 1; LDL: low-density lipoprotein; LOX-1: oxidized low density lipoprotein receptor 1; LPS: lipopolysaccharide; n-3 FA: omega-3 fatty acids; NPD1: neuroprotectin D1; PAI-1: plasminogen activator inhibitor 1; PUFAs: polyunsaturated fatty acids; TLR4: toll-like receptor 4;

TXA2R: thromboxane A2 receptor; VCAM-1: vascular cell adhesion molecule-1
\end{abstract}

\section{Acknowledgements}

Not applicable.

\section{Funding}

There was no funding available for this manuscript.

\section{Availability of data and materials}

Not applicable.

\section{Authors' contributions}

The contributed of the author for this paper. Authors read and approved the final manuscript

\section{Competing interests}

The authors have no conflicts of interest.

\section{Consent for publication}

Not applicable.

\section{Ethics approval and consent to participate}

Not applicable.

Received: 21 May 2017 Accepted: 8 June 2017

Published online: 15 June 2017

\section{References}

1. Bang HO, Dyerberg J, Hjorne N. Composition of food consumed by greenland eskimos. Acta Med Scand. 1976;200:69-73.

2. Bang HO, Dyerberg J, Nielsen AB. Plasma lipid and lipoprotein pattern in Greenlandic west-coast Eskimos. Lancet. 1971;1(7710):1143-5.

3. Dyerberg J, Bang HO. Haemostatic function and platelet polyunsaturated fatty acids in Eskimos. Lancet. 1979;2(8140):433-5.

4. Dyerberg J, Bang HO, Stoffersen E, Moncada S, Vane JR. Eicosapentaenoic acid and prevention of thrombosis and atherosclerosis? Lancet. 1978; 2(8081):117-9.

5. Bjerregaard P, Young TK, Hegele RA. Low incidence of cardiovascular disease among the inuit-what is the evidence? Atherosclerosis. 2003; 166:351-7.
6. Fodor JG, Helis E, Yazdekhasti N, Vohnout B. "fishing" for the origins of the "Eskimos and heart disease" story: facts or wishful thinking? Can J Cardiol. 2014;30:864-8.

7. Kromhout D, Feskens EJ, Bowles $\mathrm{CH}$. The protective effect of a small amount of fish on coronary heart disease mortality in an elderly population. Int J Epidemiol. 1995;24:340-5.

8. Morris D, Shekelle RB. Fish consumption and the 30-year risk of fatal myocardial infarction. N Engl J Med. 1997;336:1046-53.

9. Hu FB, Bronner L, Willett WC, Stampfer MJ, Rexrode KM, Albert CM, et al. Fish and omega-3 fatty acid intake and risk of coronary heart disease in women. JAMA. 2002;287:1815-21.

10. Mozaffarian D, Lemaitre RN, Kuller LH, Burke GL, Tracy RP, Sisco-vick DS. Cardiac benefits of fish consumption may depend on the type of fish meal consumed: the cardiovascular health study. Circulation. 2003;107:1372-7.

11. Ascherio A, Rimm EB, Stampfer MJ, Giovannucci EL, Willett WC. Dietary intake of marine $\mathrm{n} 3$ fatty acids, fish intake, and the risk of coronary disease among men. N Engl J Med. 1995:332:977-82.

12. Osler $M$, Andreasen $A H$, Hoidrup $S$. No inverse association between fish consumption and risk of death from all-causes, and incidence of coronary heart disease in middle-aged. Danish adults J Clin Epidemiol. 2003;56:274-9.

13. He K, Song Y, Daviglus ML, Liu K, Van Horn L, Dyer AR, et al. Accumulated evidence on fish consumption and coronary heart disease mortality:a metaanalysis of cohort studies. Circulation. 2004;109:2705-11.

14. Nestel $P$, Clifton $P$, Colquhoun D, Noakes M, Mori TA, Sullivan D, et al. Indications for omega-3 long chain polyunsaturated fatty acid in the prevention and treatment of cardiovascular disease. Heart Lung Circ. 2015; 24:769-79.

15. Kiage JN, Sampson UK, Lipworth L. Fazio S4, Mensah GA, Yu Q, Munro H, Akwo EA, Dai Q, Blot WJ. Kabagambe EK Intake of polyunsaturated fat in relation to mortality among statin users and non-users in the Southern Community Cohort Study Nutr Metab Cardiovasc Dis. 2015;25:1016-24.

16. Pawlosky RJ, Hibbeln JR, Novotny JA, Salem N Jr. Physiological compartmental analysis of alpha-linolenic acid metabolism in adult humans. J Lipid Res. 2001;42:1257-65.

17. Burdge GC, Calder PC. Dietary alpha-linolenic acid and health-related outcomes: a metabolic perspective. Nutr Res Rev. 2006;19:26-52.

18. Wall R, Ross RP, Fitzgerald GF, Stanton C. Fatty acids from fish: the antiinflammatory potential of long-chain omega-3 fatty acids. Nutr Rev. 2010;68:280-9.

19. Russo GL. Dietary n-6 and n-3 polyunsaturated fatty acids: from biochemistry to clinical implications in cardiovascular prevention. Biochem Pharmacol. 2009;77:937-46.

20. Baum SJ, Kris-Etherton PM, Willett WC, Lichtenstein AH, Rudel LL, Maki KC, et al. Fatty acids in cardiovascular health and disease: a comprehensive update. J Clin Lipidol. 2012;6:216-34.

21. Willett WC. Dietary fats and coronary heart disease. J Intern Med. 2012;272:13-24.

22. de Oliveira, Otto MC, Wu JH, Baylin A, Vaidya D, Rich SS, Tsai MY, Jacobs DR Jr, Mozaffarian D. Circulating and dietary omega-3 and omega-6 polyunsaturated fatty acids and incidence of CVD in the Multi-Ethnic Study of Atherosclerosis. J Am Heart Assoc. 2013;2(6):e000506.

23. Sacks FM, Katan M. Randomized clinical trials on the effects of dietary fat and carbohydrate on plasma lipoproteins and cardiovascular disease. Am J Med. 2002:113 Suppl 9B, 13S-24S.

24. Calder PC. Polyunsaturated fatty acids, inflammation, and immunity. Lipids. 2001:36:1007-24.

25. Calder PC. The role of marine omega-3 ( $n-3$ ) fatty acids in inflammatory processes, atherosclerosis and plaque stability. Mol Nutr Food Res. 2012; 56:1073-80

26. Geleijnse JM, Giltay EJ, Grobbee DE, Donders AR, Kok FJ. Blood pressure response to fish oil supplementation: meta-regression analysis of randomized trials. J Hypertens. 2002;20:1493-9.

27. Vericel E, Colas R, Calzada C, Le QH, Feugier N, Cugnet C, et al. Moderate oral supplementation with docosahexaenoic acid improves platelet function and oxidative stress in type 2 diabetic patients. Thromb Haemost. 2015;114:289-96.

28. Abeywardena MY, Head RJ. Longchain n-3 polyunsaturated fatty acids and blood vessel function. Cardiovasc Res. 2001;52:361-71.

29. Balakumar P, Taneja G. Fish oil and vascular endothelial protection: bench to bedside. Free Radic Biol Med. 2012;53:271-9.

30. Chen H, Li D, Chen J, Roberts GJ, Saldeen T, Mehta JL. EPA and DHA attenuate ox-LDL-induced expression of adhesion molecules in human 
coronary artery endothelial cells via protein kinase B pathway. J Mol Cell Cardiol. 2003;35:769-75.

31. Kataoka H, Kume N, Miyamoto S, Minami M, Moriwaki H, Murase T, et al. Expression of lectinlike oxidized low-density lipoprotein receptor-1 in human atherosclerotic lesions. Circulation. 1999;99:3110-7.

32. Xu S, Ogura S, Chen J, Little PJ, Moss J, Liu P. LOX-1 in atherosclerosis: biological functions and pharmacological modifiers. Cell Mol Life Sci. 2012 70:2859-72.

33. Yamagata K, Suzuki S, Tagami M. Docosahexaenoic acid prevented tumor necrosis factor alpha-induced endothelial dysfunction and senescence. Prostaglandins Leukot Essent Fatty Acids. 2016;104:11-8.

34. Wang TM, Chen CJ, Lee TS, Chao HY, Wu W.H, Hsieh SC, Sheu HH, Chiang AN. Docosahexaenoic acid attenuates VCAM-1 expression and NF-KB activation in TNF-a-treated human aortic endothelial cells. J Nutr Biochem 2011:221:87-194.

35. Davenport AP, Alexander SP, Sharman JL, Pawson AJ, Benson HE, Monaghan AE, et al. International Union of Basic and Clinical Pharmacology. LXXXVIII. G protein-coupled receptor list: recommendations for new pairings with cognate ligands. Pharmacol Rev. 2013;65:967-86.

36. Chao CY, Lii CK, Ye SY, Li CC, Lu CY, Lin AH, et al. Docosahexaenoic acid inhibits vascular endothelial growth factor (VEGF)-induced cell migration via the GPR120/PP2A/ ERK1/2/eNOS signaling pathway in human umbilical vein endothelial cells. J Agric Food Chem. 2014;62:4152-8.

37. Hirasawa A, Tsumaya K, Awaji T, Katsuma S, Adachi T, Yamada M, et al. Free fatty acids regulate gut incretin glucagon-like peptide-1 secretion through GPR120. Nat Med. 2005;11:90-4.

38. Im DS. Functions of omega-3 fatty acids and FFA4 (GPR120) in macrophages. Eur J Pharmacol. 2016;785:36-43.

39. Vanhoutte PM, Shimokawa H, Feletou M, Tang EH. Endothelial dysfunction and vascular disease - a 30th anniversary update. Acta Physiol (Oxf). 2017;219:22-96.

40. Fleming JA, Kris-Etherton PM. The evidence for a-linolenic acid and cardiovascular disease benefits: comparisons with eicosapentaenoic acid and docosahexaenoic acid. Adv Nutr. 2014;5:863S-76S.

41. Khanapure SP, Garvey DS, Janero DR, Letts LG. Eicosanoids in inflammation: biosynthesis, pharmacology, and therapeutic frontiers. Curr Top Med Chem. 2007:7:311-40

42. Adkins Y, Kelley DS. Mechanisms underlying the cardioprotective effects of omega-3 polyunsaturated fatty acids. J Nutr Biochem. 2010;21:781-92.

43. Mozaffarian $\mathrm{D}, \mathrm{Wu} \mathrm{JH}$. (n-3) fatty acids and cardiovascular health: are effects of EPA and DHA sharedor complementary? J Nutr. 2012;142:614S-25S.

44. Widlansky ME, Gokce N, Keaney JF Jr, Vita JA. The clinical implications of endothelial dysfunction. J Am Coll Cardiol. 2003:42:1149-60.

45. Endemann DH, Schiffrin EL. Endothelial dysfunction. J Am Soc Nephrol. 2004;15:1983-92.

46. Vanhoutte PM. Endothelial dysfunction: the first step toward coronary arteriosclerosis. Circ J. 2009;73:595-601.

47. Yeboah J, Crouse JR, Hsu FC, Burke GL, Herrington DM. Brachial flowmediated dilation predicts incident cardiovascular events in older adults: the cardiovascular health study. Circulation. 2007;115:2390-7.

48. Giansante C, Fiotti N. Insights into human hypertension: the role of endothelial dysfunction. J Hum Hypertens. 2006:20:725-6.

49. Yang Z, Ming X-F. Recent advances in understanding endothelial dysfunction in atherosclerosis. Clin Med Res. 2006;4:53-65.

50. Cosentino F, Volpe M. Hypertension, stroke, and endothelium. Curr Hypertens Rep. 2005;7:68-71.

51. Michel T, Vanhoutte PM. Cellular signaling and NO production. Pflugers Arch. 2010;459:807-16.

52. Davignon J, Ganz P. Role of endothelial dysfunction in atherosclerosis. Circulation. 2004;109(23 Suppl 1):III27-32.

53. Stebbins CL, Stice JP, Hart CM, Mbai FN, Knowlton AA. Effects of dietary decosahexaenoic acid (DHA) on eNOS in human coronary artery endothelial cells. J Cardiovasc Pharmacol Ther. 2008;13:261-8.

54. Yang YC, Lii CK, Wei YL, Li CC, Lu CY, Liu KL, et al. Docosahexaenoic acid inhibition of inflammation is partially via cross-talk between Nrf2/heme oxygenase 1 and IKK/NF-KB pathways. J Nutr Biochem. 2013;24:204-12.

55. Liu KL, Yang YC, Yao HT, Chia TW, Lu CY, Li CC, et al. Docosahexaenoic acid inhibits inflammation via free fatty acid receptor FFA4, disruption of TAB2 interaction with TAK1/TAB1 and downregulation of ERK-dependent Egr-1 expression in EA.hy926 cells. Mol Nutr Food Res. 2016;60:430-43.

56. Williams-Bey Y, Boularan C, Vural A, Huang NN, Hwang IY, Shan-Shi C, et al. Omega-3 free fatty acids suppress macrophage inflammasome activation by inhibiting NF-KB activation and enhancing autophagy. PLoS One. 2014;9: e97957.

57. Moniri NH. Free-fatty acid receptor-4 (GPR120): Cellular and molecular function and its role in metabolic disorders. Biochem. Pharmacol. 2016;110111, 1-15.

58. Yagi S, Aihara K, Fukuda D, Takashima A, Hara T, Hotchi J, et al. Effects of docosahexaenoic acid on the endothelial function in patients with coronary artery disease. J Atheroscler Thromb. 2015;22:447-54.

59. Oh DY. Walenta E, Akiyama TE, Lagakos WS, lackey D, Pessentheiner AR, Sasik R, hah N, chi TJ, cox JM, Powels MA, di salvo J, Sinz C, Watkins SM, Armando AM, Chung H, RM, Quehenberger O, McNelis J, Bogner-Strauss JG, Olefsky JM. A Gpr120-selective agonist improves insulin resistance and chronic inflammation in obese mice. Nat Med. 2014;20:942-7.

60. O'Connell TD, Block RC, Huang SP, Shearer GC. w3-polyunsaturated fatty acids for heart failure: effects of dose on efficacy and novel signaling through free fatty acid receptor 4. J Mol Cell Cardiol. 2017;103:74-92.

61. Huang CY, Sheu WH, Chiang AN. Docosahexaenoic acid and eicosapentaenoic acid suppress adhesion molecule expression in human aortic endothelial cells via differential mechanisms. Mol Nutr Food Res. 2015;59:751-62.

62. Mori TA. Dietary n-3 PUFA and CVD: a review of the evidence. Proc Nutr Soc. 2014;73:57-64.

63. Qi K, Fan C, Jiang J, Zhu H, Jiao H, Meng Q, et al. Omega-3 fatty acid containing diets decrease plasma triglyceride concentrations in mice by reducing endogenous triglyceride synthesis and enhancing the blood clearance of triglyceride-rich particles. Clin Nutr. 2008;27:424-30.

64. Lovegrove JA, Lovegrove SS, Lesauvage SV, Brady LM, Saini N, Minihane AM, et al. Moderate fish-oil supplementation reverses low-platelet, long-chain n3 polyunsaturated fatty acid status and reduces plasma triacylglycerol concentrations in British indo-Asians. Am J Clin Nutr. 2004;79:974-82.

65. Jump DB. Fatty acid regulation of hepatic lipid metabolism. Curr Opin Clin Nutr Metab Care. 2011;14:115-20.

66. Harris WS, Bulchandani D. Why do omega-3 fatty acids lower serum triglycerides? Curr Opin Lipidol. 2006;17:387-93.

67. Zulyniak MA, Perreault M, Gerling C, Spriet LL, Mutch DM. Fish oil supplementation alters circulating eicosanoid concentrations in young healthy men. Metabolism. 2013;62:1107-13.

68. Honda KL, Lamon-Fava S, Matthan NR, Wu D, Lichtenstein AH. Docosahexaenoic acid differentially affects TNFa and IL-6 expression in LPSstimulated RAW 264.7 murine macrophages. Prostaglandins Leukot Essent Fatty Acids. 2015;97:27-34

69. Wang Z, Guo A, Ma L, Yu H, Zhang L, Meng H, et al. Docosahexenoic acid treatment ameliorates cartilage degeneration via a p38 MAPK-dependent mechanism. Int J Mol Med. 2016:37:1542-450.

70. Wang B, Wu XW, Guo MX, Li ML, Xu XB, Jin XX, et al. Effects of $\omega-3$ fatty acids on toll-like receptor 4 and nuclear factor-KB p56 in severe acute pancreatitis in lung of rats. World J Gastroenterol. 2016;22:9784-93.

71. Ibrahim A, Mbodji K, Hassan A, Aziz M, Boukhettala N, Coeffier M, et al. Anti-inflammatory and anti-angiogenic effect of long chain n-3 polyunsaturated fatty acids in intestinal microvascular endothelium. Clin Nutr. 2011;30:678-87.

72. Liu HQ, Qiu Y, Mu Y, Zhang XJ, Liu L, Hou XH, et al. A high ratio of dietary n-3/n-6 polyunsaturated fatty acids mproves obesity-linked inflammation and insulin resistance through suppressing activation of TLR4 in SD rats. Nutr Res. 2013:33:849-58.

73. Bucher HC, Hengstler P, Schindler C, Meier G. N-3 polyunsaturated fatty acids in coronary heart disease:a meta-analysis of randomized controlled trials. Am J Med. 2002;112:298-304.

74. He K, Song Y, Daviglus ML, Liu K, Van Horn L, Dyer AR, et al. Accumulated evidence on fish consumption and coronary heart disease mortality - a meta-analysis of cohort studies. Circulation. 2004;109:2705-11.

75. Whelton SP, He J, Whelton PK, Muntner P. Meta-analysis of observational studies n fish intake and coronary heart disease. Am J Cardiol. 2004;93: $1119-23$.

76. Wang C, Harris WS, Chung M, Lichtenstein AH, Balk EM, Kupelnick B, et al. $\mathrm{N}-3$ fatty acids from fish or fish-oil supplements, but not alphalinolenic acid, benefit cardiovascular disease outcomes in primary- and secondaryprevention studies: a systematic review. Am J Clin Nutr. 2006;84:5-17.

77. He K, Song YQ, Daviglus ML, Liu K, Van Horn L, Dyer AR, et al. Fish consumption and incidence of stroke - a meta-analysis of cohort studies. Stroke. 2004;35:1538-42. 
78. Xun P, Qin B, Song Y. Nakamura Y, Kurth T, Yaemsiri S, Djousse L, He K. Fish consumption and risk of stroke and its subtypes: accumulative evidence from a meta-analysis of prospective cohort studies. Eur J Clin Nutr 2012;66: 1199-1207.

79. Burr ML, Gilbert JF, Holliday RM, Sweetnam PM, Elwood PC, Deadman NM. Effects of changes in fat, fish, and fiber intakes on death and myo- cardial reinfarction - diet and reinfarction trial (dart). Lancet. 1989;2:757-61.

80. Valagussa F, Franzosi MG, Geraci E. Dietary supplementation with n-3 polyunsaturated fatty acids and vitamin $\mathrm{E}$ after myocardial infarction: results of the GISSI-Prevenzione trial. Lancet. 1999;354:447-55.

81. Yokoyama M, Origasa H, Matsuzaki M, Matsuzawa Y, Saito Y, Ishikawa Y, Oikawa S, Sasaki J, Hishida H, Itakura H, Kita T, Kitabatake A, Nakaya N, Sakata T, Shimada K, Shirato K, Japan EPA lipid intervention study (JELIS). Investigators. Effects of eicosapentaenoic acid on major coronary events in hypercholesterolaemic patients (JELIS): a randomised openlabel, blinded endpoint analysis. Lancet 2007;369:1090-1098.

82. Tavazzi L, Maggioni AP, Marchioli R, Barlera S, Franzosi MG, et al. Effect of n3 polyunsaturated fatty acids in patients with chronic heart failure (the GISSI-HF trial): a randomised, double-blind, placebo-controlled trial. Lancet. 2008;372:1223-30

83. Bosch J, Gerstein HC, Dagenais GR, Diaz R, Dyal L, et al. N-3 fatty acids and cardiovascular outcomes in patients with dysglycemia. ORIGIN trial Investigators. N Engl J Med. 2012;367:309-18.

84. Mozaffarian D, Marchioli R, Macchia A, Silletta MG, Ferrazzi P, Gardner TJ, et al. Fish oil and postoperative atrial fibrillation: the omega-3 fatty acids for prevention of post-operative atrial fibrillation (OPERA) randomized trial. JAMA. 2012;308:2001-11.

85. Risk and Prevention Study Collaborative Group. n-3 fatty acids in patients with multiple cardiovascular risk factors. N Engl J Med. 2013;368:1800-8.

86. Sekikawa A, Curb JD, Ueshima H, El-Saed A, Kadowaki T, Abbott RD, Evans RW, Rodriguez BL, Okamura T, Sutton-Tyrrell K, Nakamura Y, Masaki K, Edmundowicz D, Kashiwagi A, Willcox BJ, Takamiya T, Mitsunami K, Seto TB, Murata K, White RL, Kuller LH. ERA JUMP (Electron-Beam tomography, Risk factor assessment among japanese and U.S. Men in the post-world war II birth cohort) study group. Marine-derived n-3 fatty acids and atherosclerosis in Japanese, Japanese-American, and white men: a cross-sectional study. J Am Coll Cardiol. 2008;52:417-24.

87. Harris W. Omega-3 fatty acids: the "Japanese" factor? J Am Coll Cardiol. 2008:52:425-7.

88. Van Noolen L, Back M, Arnaud C, Rey A, Petri MH, Levy P, et al. Docosahexaenoic acid supplementation modifies fatty acid incorporation in tissues and prevents hypoxia induced-atherosclerosis progression in apolipoprotein-E deficient mice. Prostaglandins Leukot Essent Fatty Acids. 2014;91:111-7.

89. Gladine C, Newman JW, Durand T, Pedersen TL, Galano JM, Demougeot C, Berdeaux O, Pujos-Guillot E, Mazur A, Comte B. Lipid profiling following intake of the omega 3 fatty acid DHA identifies the peroxidized metabolites F4-neuroprostanes as the best predictors of atherosclerosis prevention. PLoS One 2014;9, e89393.

90. Bphinaa KH, Bjerve KS, Straume B, Gram IT, Thelle D. Effect of eicosapentaenoic and docosahexaenoic acids on blood pressure in hypertension. A population-based intervention trial from the Tromsphi study. N Engl J Med. 1990;322:795-801.

91. Ueshima H, Stamler J, Elliott P, Chan Q, Brown IJ, Carnethon MR, et al. Food omega-3 fatty acid intake of individuals (total, linolenic acid, long-chain) and their blood pressure: INTERMAP study. Hypertension. 2007;50:313-9.

92. Miller PE, Van Elswyk M, Alexander DD. Long-chain omega-3 fatty acids eicosapentaenoic acid and docosahexaenoic acid and blood pressure:a metaanalysis of randomized controlled trials. Am J Hypertens. 2014;27:885-96.

93. Mori TA, Bao DQ, Burke V, Puddey IB, Beilin LJ. Docosahexaenoic acid but not eicosapentaenoic acid lowers ambulatory blood pressure and heart rate in humans. Hypertension. 1999;34:253-60.

94. Woodman RJ, Mori TA, Burke V, Puddey IB, Watts GF, Beilin LJ. Effects of purified eicosapentaenoic and docosahexaenoic acids on glycemic control, blood pressure, and serum lipids in type 2 diabetic patients with treated hypertension. Am J Clin Nutr. 2002;76:1007-15.

95. Grynberg A. Hypertension prevention: from nutrients to (fortified) foods to dietary patterns. Focus on fatty acids. J Hum Hypertens. 2005;19(Suppl 3):S25-33.

96. Frenoux JM, Prost ED, Belleville JL, Prost JL. A polyunsaturated fatty acid diet lowers blood pressure and improves antioxidant status in spontaneously hypertensive rats. J Nutr. 2001;131:39-45.
97. Minihane AM, Armah CK, Miles EA, Madden JM, Clark AB, Caslake MJ, et al Consumption of fish oil providing amounts of eicosapentaenoic acid and docosahexaenoic acid that can be obtained from the diet reduces blood pressure in adults with systolic hypertension: a retrospective analysis. J Nutr. 2016;146:516-23.

98. Zhao YT, Chen Q, Sun YX, Li XB, Zhang P, et al. Prevention of sudden cardiac death with omega-3 fatty acids in patients with coronary heart disease: a meta-analysis of randomized controlled trials. Ann Med. 2009; 41:301-10.

99. Zheng J, Huang T, Yu Y, Hu X, Yang B, Li D. Fish consumption and CHD mortality: an updated meta-analysis of seventeen cohort studies. Public Health Nutr. 2012;15:725-37.

100. Shoji T, Kakiya R, Hayashi T, Tsujimoto Y, Sonoda M, Shima H, et al. Serum n-3 and n-6 polyunsaturated fatty acid profile as an independent predictor of cardiovascular events in hemodialysis patients. Am J Kidney Dis. 2013;62:568-76.

101. Davidson MH, Benes LB. The future of $n-3$ polyunsaturated fatty acid therapy. Curr Opin Lipidol. 2016;27:570-8.

102. Fahs CA, Yan H, Ranadive S, Rossow LM, Agiovlasitis S, Wilund KR, et al. The effect of acute fish-oil supplementation on endothelial function and arterial stiffness following a high-fat meal. Appl Physiol Nutr Metab. 2010;35:294-302.

103. Walser B, Giordano RM, Stebbins CL. Supplementation with omega-3 polyunsaturated fatty acids augments brachial artery dilation and blood flow during forearm contraction. Eur J Appl Physiol. 2006;97:347-54.

104. Ferreira ED, Romanini CV, de Oliveira JN, Previdelli IT, de Melo SR, de Oliveira RM, et al. Fish oil provides a sustained antiamnesic effect after acute, transient forebrain ischemia but not after chronic cerebral hypoperfusion in middle-aged rats. Behav Brain Res. 2014;265:101-10.

105. Hong SH, Belayev L, Khoutorova L, Obenaus A, Bazan NG. Docosahexaenoic acid confers enduring neuroprotection in experimental stroke. J Neurol Sci. 2014;338:135-41.

106. Chang CY, Kuan YH, Li JR, Chen WY, Ou YC, Pan HC, et al. Docosahexaenoic acid reduces cellular inflammatory response following permanent focal cerebral ischemia in rats. J Nutr Biochem. 2013;24:2127-37.

107. Suda S, Katsumata T, Okubo S, Kanamaru T, Suzuki K, Watanabe Y, et al. Low serum n-3 polyunsaturated fatty acid/n-6 polyunsaturated fatty acid ratio predicts neurological deterioration in Japanese patients with acute ischemic stroke. Cerebrovasc Dis. 2013;36:388-93.

108. Song TJ, Chang Y, Shin MJ, Heo JH, Kim YJ. Low levels of plasma omega 3polyunsaturated fatty acids are associated with cerebral small vessel diseases in acute ischemic stroke patients. Nutr Res. 2015;35:368-74.

109. Ajami M, Eghtesadi S, Razaz JM, Kalantari N, Habibey R, Nilforoushzadeh MA et al. Docosahexaenoic acid inhibition of inflammation is partially via crosstalk between Nrf2/heme oxygenase 1 and IKK/NF-KB pathways. J Nutr Biochem. 2013;24:204-12.

110. Litman BJ, Niu SL, Polozova A, Mitchell DC. The role of docosahexaenoic acid containing phospholipids in modulating $\mathrm{G}$ protein-coupled signaling pathways: visual transduction. J Mol Neurosci. 2001;16:237-42.

111. Moriguchi T, Salem N Jr. Recovery of brain docosahexaenoate leads to recovery of spatial task performance. J Neurochem. 2003;87:297-309.

112. Stinson AM, Wiegand RD, Anderson RE. Recycling of docosahexaenoic acid in rat retinas during n-3 fatty acid deficiency. J Lipid Res. 1991;32:2009-17.

113. Belayev L, Khoutorova L, Atkins KD, Bazan NG. Robust docosahexaenoic acid-mediated neuroprotection in a rat model of transient, focal cerebral ischemia. Stroke. 2009;40:3121-6.

114. Bazan NG. Neuroprotectin D1-mediated anti-inflammatory and survival signaling in stroke, retinal degenerations, and Alzheimer's disease. J. Lipid Res. 2009;50 Suppl, S400-S4005. 